\title{
Effectiveness of Foot Reflex Therapy in Post-Operative Pain among Patients Subjected to Major Abdominal Surgery
}

\author{
Poongodi Ramalingam¹, Ramya Ramakrishnan², Rajeswari Singaravelu³, Aruna Subramaniam4
}

1,4 Department of Community Health Nursing, Sri Ramchandra College of Nursing, Sri Ramachandra Institute of Higher Education And Research (Du), Porur, Chennai, Tamil Nadu, India. ${ }^{2}$ Department of General Surgery, Sri Ramachandra Medical College and Research Institute, Sri Ramachandra Institute of Higher Education And Research (Du), Porur, Chennai, Tamil Nadu, India. ${ }^{3}$ Department of Obstetrics and

Gynaecological Nursing, Sri Ramchandra College of Nursing, Sri Ramachandra Institute of Higher Education and Research (Du), Porur, Chennai, Tamil Nadu, India.

\section{ABSTRACT}

\section{BACKGROUND}

Most patients experience post-operative pain and it is unavoidable. It is the duty of the nurses to ensure that patients' pain is assessed and managed effectively when they are at the hospital. Foot reflex therapy is one effective way nurses can adopt to manage the patient with pain after surgery. We wanted to evaluate the effectiveness of foot reflex therapy on post-operative pain in patients who are subjected to major abdominal surgery.

\section{METHODS}

This is a descriptive randomized control study that was conducted at Sri Ramachandra Medical College and Hospital, among 360 patients who underwent major abdominal surgery. They were equally divided into two groups as control and study groups and the results were analyzed statistically.

\section{RESULTS}

Majority of the patients in the study group showed a positive effect on pain control during $4^{\text {th }}$ and $5^{\text {th }}$ [(Mean: 1.27 with SD: 1.12 ) (Mean: 0.03 with SD: 0.32) at $p<0.001$ ] post-operative day following foot reflex therapy.

\section{CONCLUSIONS}

The existing pain and the post-operative pain can be managed by nurses, patients, their care takers or families together, whenever appropriate, in a multidisciplinary manner. Foot reflex therapy is one such alternative complementary therapy which the nurses can adopt to implement the techniques independently.

\section{KEY WORDS}

Foot Reflex Therapy, Foot Reflexology, Alternative Medicine, Complementary Therapy, Post-Operative Day (POD)
Corresponding Author: Dr. Poongodi Ramalingam, Sri Ramachandra College of Nursing, Sri Ramachandra Institute of Higher Education and Research (DU), Porur, Chennai, Tamil Nadu, India.

E-mail: poongodimohan@sriramachandra.edu.in

DOI: $10.14260 /$ jemds/2020/727

How to Cite This Article: Ramalingam $P$, Ramakrishnan $R$. Singaravelu $R$, et al Effectiveness of foot reflex therapy in post-operative pain among patients subjected to major abdominal surgery. J Evolution Med Dent Sci 2020;9(44):3310-3314, DOI: $10.14260 /$ jemds/2020/727

Submission 29-07-2020,

Peer Review 25-09-2020,

Acceptance 01-10-2020,

Published 02-11-2020.

Copyright (C) 2020 Poongodi Ramalingam et al. This is an open access article distributed under Creative Commons Attribution License [Attribution 4.0 International (CC BY 4.0)] 


\section{BACKGROUND}

Pain is the first and most frequent complication following any surgical procedure. ${ }^{1}$ It refers to the subjective physical discomfort experienced due to tissue trauma by the patient after a major abdominal surgery as measured using the Visual Analog Scale (VAS) and reflected by physiological parameters which includes pulse rate, respiratory rate, blood pressure and oxygen saturation. ${ }^{2}$ Pain management in hospitals becomes a major factor to attend especially after major surgeries as it greatly influences the treatment outcome and it affects the patients psychology which cause threat to their comfort. ${ }^{3}$ Experience of discomfort over a period of time hampers a person's self-care and role obligations that can impair the quality of life. ${ }^{4}$ Pain can cause personal hardships and it is the most common reason for physician consultation all over the world. ${ }^{5}$ It is also a major symptom in various medical and surgical conditions that significantly interferes with a person's quality of life.

The only management of pain which many people cannot cope up is through surgical procedure. Pain when cannot be managed adequately it will cost more for the patient, their families and society. ${ }^{6}$ The common pain in the abdominal surgery is the post-operative pain which is also a symptom of warning. ${ }^{7}$ Analgesics and anaesthetic techniques are available to control the post-operative pain. Still the prevalence rate of pain after surgery is reported high.

Post-operative pain is very common and around $80 \%$ of the patients are reporting pain after surgery. Another study on patients who underwent various surgeries like abdominal, spinal and extremity surgery complained severe pain after the surgical procedure. ${ }^{9}$ It was noted that most of the patients expressed more pain during day 0 , A similar study reported that the percentage of postoperative pain experienced by patients after abdominal surgery varied from $22 \%$ to $67 \%$ and was severe to unbearable pain. ${ }^{10}$ Preoperative pain and poorly controlled postoperative pain have been in high association with development of chronic postsurgical pain.

One of the effective ways to manage pain is to administer analgesics (NSAIDs or opioid analgesics). While pain relief may sometimes be inadequate with the use of analgesics, development and improvement of alternative interventions became necessary for a more effective pain control strategy.11,12 Foot reflex therapy, a modified form of reflexology is an effective, acceptable and complementary intervention. ${ }^{13}$ To find the impact on foot reflex therapy in post-operative surgical pain control, there is very less data available, thus this study focuses on determining the effectiveness of foot reflex therapy on post-operative pain following major abdominal surgeries.

\section{METHODS}

This descriptive randomized control study was conducted at the Department of General surgery, Sri Ramachandra Medical College Hospital, Porur, Chennai during the time period Jan 2012 to Sep 2013. The target population of the study included patients who underwent major abdominal surgery between the age group 20 and 60 years. The sample comprised of 360 patients equally distributed among the control and study groups. The sample size was determined by power analysis and effect size. The patients who underwent abdominal surgery were included in this study. Subjects were included based on their willingness. Patients who had foot wounds, burns infections, deep vein thrombosis, who had history of removal of malignant tumour, who has underwent laparoscopic abdominal surgery were not included in the study. The investigator used Visual Numeric Pain Scale to assess the pain in patients in study and the control groups. Minimum score in Visual Numeric Pain Intensity Scale is 0 and maximum score is 10 . The pain intensity was classified for the visual analogue scale is as follows: 0 - no pain, 1 to 3 - mild pain, 4 to 6 - moderate pain and 7 to 10 - severe pain.

The pain scale was administered during the preassessment and the post-assessment of foot reflex therapy from $1^{\text {st }}$ to $5^{\text {th }}$ post-operative day. Foot reflex therapy was provided by a foot reflex therapist for 30 minutes per day from the $1^{\text {st }}$ to $5^{\text {th }}$ post-operative day and thereafter the procedures has been carried out by the patient's caregivers for a period of 21 days at their home.

Foot reflex therapy performance was classified into 3 categories. The total score range from 1 to 24 . A score of one was given for correct performance and zero for wrong performance. The level of practice was grouped as follows: 71 to $100 \%$ - satisfactory practice, 34 - $70 \%$ - moderate satisfactory practice and $<33 \%$ is poor practice. Data was collected in three phases and analysed statistically using paired ' $t$ ' test.

\section{RESULTS}

The study was conducted among 360 patients who underwent major abdominal surgery under general anaesthesia. They were divided into two groups of 180 each as study group and control group. The major abdominal surgeries that were included in this study are inguinal hernia (37.44\% in study group and $40 \%$ in control group), incisional hernia (30.55\% in study group and $33.33 \%$ in control group), umbilical hernia (16.66 \% in study group and $19.46 \%$ in control group), appendicectomy (5.56 \% in study group and $1.66 \%$ in control group) and cholecystectomy (9.46\% in study group and 5.55 $\%$ in control group) [Figure 1]

Hypertension was the most commonly existing comorbid condition in this study followed by diabetes mellitus. Hypothyroidism and asthma were also observed in a few patients. A majority of the patients in both the groups did not have any existing comorbid conditions. Foot reflex therapy was given to the patients in the study group and their pre and post-test pain scores were assessed. The mean pain scores in the study group and control group during the $1^{\text {st }}$ and $5^{\text {th }}$ postoperative day is 6.23 to 0.03 and 7.01 to 1.31 respectively.

On day 1 majority of the samples, 84 (46.7\%) in the study group and 139 (41.68\%) in the control group had severe pain. $92(51.1 \%)$ in the study and $40(56.66 \%)$ in the control group had moderate level of pain. 4 (2.2\%) in the study and $1(0.66$ $\%)$ in the control had reported mild pain. All of them reported pain during pre-test. The $\mathrm{p}$ value indicated the homogeneity between the group. During post-test majority of the study group samples 135 (75\%) reported moderate pain whereas in the control group 117 (65\%) of them reported severe pain. 


\begin{tabular}{|lcccccc|}
\hline & $\begin{array}{c}\text { Duration of } \\
\text { the Study }\end{array}$ & Mean & SD & $\begin{array}{c}\text { Mean } \\
\text { Difference }\end{array}$ & $\begin{array}{c}\text { Paired t } \\
\text { Value }\end{array}$ & $\begin{array}{c}\text { (P- } \\
\text { Value) }\end{array}$ \\
Day 1 & Pre-test & 6.23 & 1.36 & 0.28 & 5.571 & $0.000^{* * *}$ \\
& Post-test & 4.05 & 2.30 & & & \\
Day 2 & Pre-test & 5.87 & 1.11 & 2.51 & 0.45 & $0.000^{* * *}$ \\
& Post-test & 3.36 & 1.51 & & & \\
Day 3 & Pre-test & 2.88 & 1.42 & 1.16 & 8.88 & $0.000^{* * *}$ \\
& Post-test & 1.72 & 1.25 & & & \\
Day 4 & Pre-test & 3.33 & 1.53 & 2.05 & 8.45 & $0.000^{* * *}$ \\
& Post-test & 1.27 & 1.12 & & & \\
Day 5 & Pre-test & 0.66 & 0.79 & 0.62 & 11.15 & $0.000^{* * *}$ \\
& Post-test & 0.03 & 0.32 & & \\
\hline \multicolumn{7}{c}{ Table 1. Comparison of Day 1 to 5, Mean Score of Pain } \\
among Patients in the Study Group \\
*** $<$ 0.001, n = 180
\end{tabular}

\begin{tabular}{|ccccccc|}
\hline & $\begin{array}{c}\text { Duration of } \\
\text { the Study }\end{array}$ & Mean & SD & $\begin{array}{c}\text { Mean } \\
\text { Difference }\end{array}$ & $\begin{array}{c}\text { Paired t } \\
\text { Value }\end{array}$ & $\begin{array}{c}\text { (P- } \\
\text { Value) }\end{array}$ \\
Day 1 & Pre-test & 7.01 & 1.04 & 0.29 & 3.163 & $0.000^{* * *}$ \\
& Post-test & 6.72 & 1.42 & & & \\
Day 2 & Pre-test & 6.18 & 0.92 & 0.61 & 6.82 & $0.000^{* * *}$ \\
& Post-test & 5.57 & 1.49 & & & \\
Day 3 & Pre-test & 4.41 & 1.49 & 0.5 & 3.936 & $0.000^{* * *}$ \\
& Post-test & 3.92 & 1.86 & & & \\
Day 4 & Pre-test & 3.86 & 1.59 & 0.7 & 5.657 & $0.000^{* * *}$ \\
& Post-test & 3.16 & 1.74 & & & \\
Day 5 & Pre-test & 1.69 & 1.68 & 0.38 & 3.127 & $0.000^{* * *}$ \\
& Post-test & 1.31 & 1.58 & & \\
\hline \multicolumn{7}{c}{ Table 2. Comparison of Day 1 to 5, Mean Score of Pain } \\
among Patients in the Control Group & \\
\hline *** P $<0.001, \mathrm{n}=180$ \\
\hline
\end{tabular}

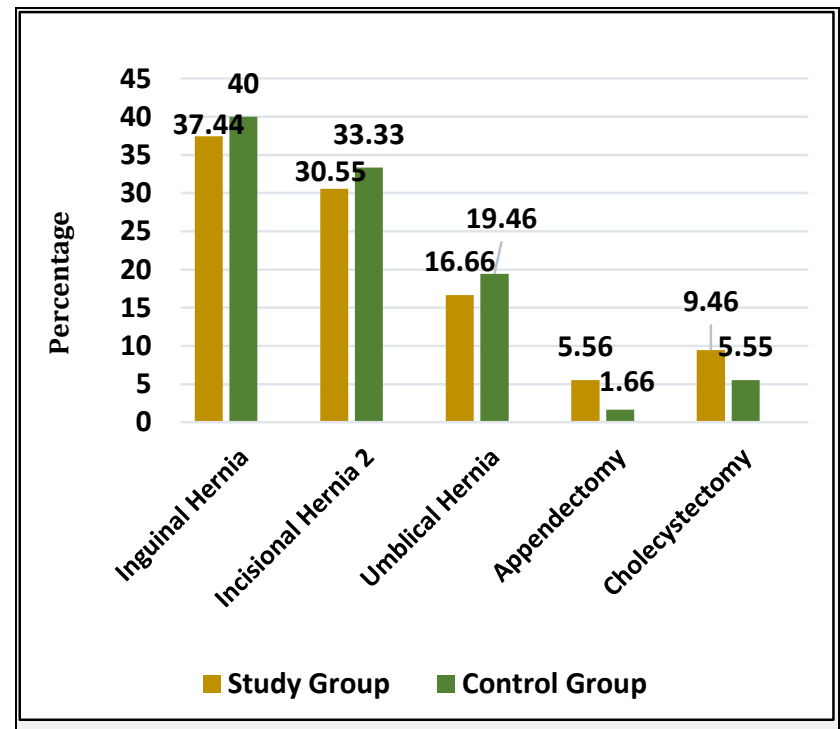

Figure 1. The Total Percentage Distribution-Type of Surgery $(N=360)$

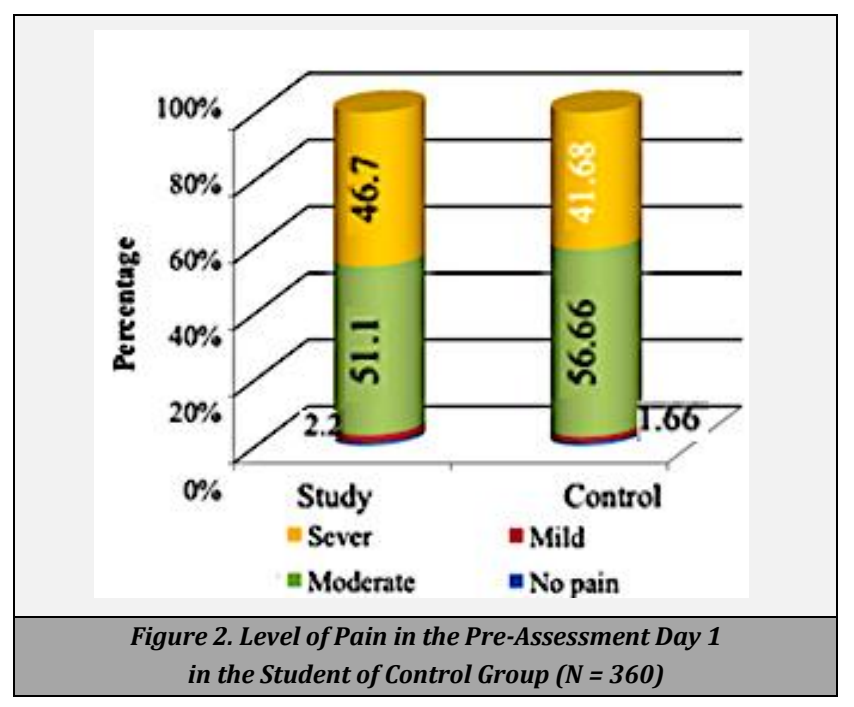

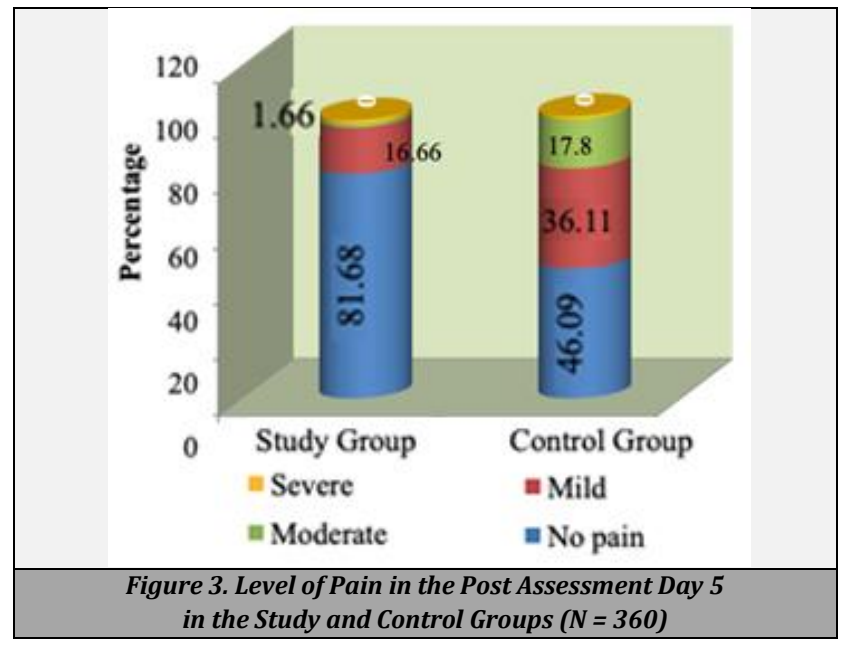

The level of severe pain had reduced $28.88 \%$ in the study group whereas in the control group, the level of reduction was only $12.22 \%$

On day 2, 64 (35.6\%) in the study group, and 70 (38.9\%) in the control group samples reported severe pain during pretest. Majority of the samples 91 (50.6\%) in the study and 119 $(66.1 \%)$ in the control group reported moderate pain during post-test. The level of severity of pain was reduced in $34.5 \%$ in the study group whereas in the control group the level of reduction was only $13.9 \%$.

On day 3, in pre-test none of them reported severe pain in the study group whereas in the control group, 13 (7.3\%) had severe pain and during post-test in the study group none of them reported severe pain and majority of the samples, 130 $(72.2 \%)$ reported mild level of pain whereas in the control group, 12 (6.7\%) of them had severe and 98 (54.7\%) of them had mild pain.

On day 4, majority of the samples 88 (48.9\%) in the study group and $107(60.1 \%)$ control group reported mild pain whereas in the post-test $116(64.4 \%)$ in the study group and $74(41.6 \%)$ in the control group reported mild pain and majority of the samples, $58(32.2 \%)$ shifted to no pain in the study group whereas in control only $13(7.3 \%)$ had a change.

On day 5, $92(51.1 \%)$ of the study group during pre-test, and the control group $59(33.1 \%)$ were reported no pain and $88(48.9 \%)$ in the study and $77(43.1 \%)$ in the control had mild pain. During post-test in study group 146 (81.1\%) had no pain and $30(16.6 \%)$ were in mild pain whereas in the control group 32 (17.8\%) were with moderate and 65 (36.11\%) reported mild pain.

The study findings conclude that patients who received foot reflex therapy in the post-operative period showed better pain recovery than patients who did not receive the therapy. [(Mean: 1.27 with SD: 1.12 ) (Mean: 0.03 with SD: 0.32 ) at $\mathrm{p}<$ $0.001]$.

\section{DISCUSSION}

Both by patient and physician, pain is the most undesired symptom in the post-operative period. ${ }^{4}$ Poorly controlled post-operative pain may affect the patient's psychological, social and mental health. It also mainly reduces the quality of life during and after the surgery. This can lead to other physiological disturbances like impaired respiration, sleep disturbances and loss of appetite. The discharge of the patient 
is delayed when the pain is not controlled on time after the surgery, which in turn impacts the cost of the healthcare, alleviation of negative pain and loss of productivity of results.

This has become a big challenge for healthcare providers which is one of the important roles in controlling the postoperative pain by managing both pharmacological and non-pharmacological pain-relieving interventions. Uncontrolled pain can lead to other serious health problems like cardiac dysrhythmias, atelectasis, pneumonia and sometimes sensory abnormalities also. ${ }^{14}$ This leads to the need for the development of complementary therapy in alleviating post-operative pain.

Several studies on complementary therapies have proven to improve the medical treatment which augment the comfort of the patient. Soothing music, relaxing on own by different methods, touch therapy, reflexology therapies, plant based medications and yoga are other alternative treatment. ${ }^{15}$ Foot reflexology was chosen as an alternative nursing intervention in this study. Earlier studies were performed to investigate the effect of reflexes on postoperative pain in cancer patients and none of the studies were on patients undergoing major abdominal surgery for benign conditions / diseases.

The Gate theory, serotonin hypothesis and the restorativesleep hypothesis ${ }^{16}$ are evident of the analgesic effects of reflexology on post-operative pain. Current study also revealed that a high percentage of severe pain was observed during the $3^{\text {rd }}$ and $4^{\text {th }}$ post-operative days. It was also noticed that the level of knowledge on usage of complementary medical practise and alternative treatment among the patients and care givers is low and $67 \%$ of them were unaware about complementary and alternative medicine use to control postoperative pain. The outcome of the present study concluded that postoperative pain is very common in post-surgical condition and available managements are difficult to be continued owing to the drug side effects.

Another study evaluated the benefit of massage therapy in improving peri-operative patient related outcomes, it revealed significant reduction of VAS scores for pain from 5.3 to 2.9 (n $=79, \mathrm{p}<0.0001$ ) and also an improved well-being from 5.2 to $6.7(n=69, p<0.0001) \cdot{ }^{17}$ One of the study examined the effectiveness of massage of hand in relation to pain, feeling and providing nursing care among 45 post-operative patients at surgical ward. Pain was assessed through visual analogue scale. The nursing support and measurement of physiological conditions was evaluated. The study findings showed a significant pain relief $(t=4.04, p=0.0001)$, improvement in feeling and an increase in skin temperature. ${ }^{18}$

The study was conducted to evaluate the neurophysiological effect on different types of body massage in healthy adults in support to functional magnetic resonance imaging methods. The outcome showed that the massage treatment activates the subgenual and posterior cingulate cortices which in turn increases the oxygen level of blood during the cognitive task performances. The results showed light on applying these new interventions might improve to plan new targets for managing pain among healthy individuals. ${ }^{19}$ Another study conducted to review the effect of reflexology on pain and outcomes of the labour in 88 primi paras mothers. In the reflexology group, there was a significant difference between the Pain Rating Index (PRI) before and after the 4 stages of intervention $(p<0.001)$. Thus, the study concluded reflexology can decrease the labour pain and also it is a safe technique and it can be replaced as an alternative for pharmacological methods to control the pain. ${ }^{20}$ The findings of this current study also lines with the outcomes of those in the previous studies. The patients showed a significant change in the mean pain scores from 4.05 in the $1^{\text {st }}$ post-operative day to 1.27 and 0.03 in the $4^{\text {th }}$ and $5^{\text {th }}$ post-operative days respectively. The pain intensity also reduced significantly in the study group in the $4^{\text {th }}$ and $5^{\text {th }}$ post-operative days to mild or no pain from severe pain in the $1^{\text {st }}$ post-operative day when compared to the control group following the massage. Hence foot reflex therapy can be used as an adjuvant therapy to relieve pain in post-operative patients.

Another study was performed among stomach cancer patients which investigated the foot reflex treatment and management as adjuvant therapy to alleviate pain and reduction of anxiety in patients with cancer and also supported to the management of postoperative pain in cancer patients. ${ }^{21}$ Thus nurses play an important role in improving the patient's health and post-operative recovery as they come in close line of contact with the patients. Foot reflex therapy can be a very good alternative complementary therapy in this accord which the nurses can offer to the patients apart from the administration of regular analgesics and other painrelieving medications.

\section{CONCLUSIONS}

Postoperative pain was reduced in patients who underwent abdominal surgery, upon treatment with foot reflex therapy. Those who received foot reflex therapy for five days post operatively and further continued the therapy being given by patient's care giver at home have produced a more significant positive effect on pain. Foot reflex therapy is an effective therapy to control acute post-operative pain and thereby improves the quality of life of patients. More specific studies should be conducted in the future about the effectiveness of foot reflex therapy in various other parameters and comparative studies can be done among types of surgery and anaesthesia.

Data sharing statement provided by the authors is available with the full text of this article at jemds.com.

Financial or other competing interests: None.

Disclosure forms provided by the authors are available with the full text of this article at jemds.com.

\section{REFERENCES}

[1] Majuta LA, Longo G, Fealk MN, et al. Orthopedic surgery and bone fracture pain are both significantly attenuated by sustained blockade of nerve growth factor. Pain 2015;156(1):157-65

[2] Vander Velpen GC, Shimi SM, Cuschieri A. Outcome after cholecystectomy for symptomatic gall stone disease and effect of surgical access: laparoscopic v open approach. Gut 1993;34(10):1448-51.

[3] McCabe C. Effective pain management in patients in hospital. Nurs Stand 2017;31(29):42-6. 
[4] Chu YF, Sun J, Wu X, et al. Antioxidant and antiproliferative activities of common vegetables. J Agric Food Chem 2002;50(23):6910-6.

[5] Turk DC, Dworkin RH. What should be the core outcomes in chronic pain clinical trials? Arthritis Res Ther 2004;6(4):151-4.

[6] Brennan F, Carr DB, Cousins M. Pain management: a fundamental human right. Anesth Analg 2007;105(1):205-21.

[7] Power I. Recent advances in postoperative pain therapy. Br J Anaesth 2005;95(1):43-51.

[8] Apfelbaum JL, Chen C, Mehta SS, et al. Postoperative pain experience: results from a national survey suggest postoperative pain continues to be undermanaged. Anesth Analg 2003;97(2):534-40.

[9] Sommer M, de Rijke JM, van Kleef M, et al. The prevalence of postoperative pain in a sample of 1490 surgical inpatients. Eur J Anaesthesiol 2008;25(4):267-74.

[10] Vallano A, Aguilera C, Arnau JM, et al. Management of postoperative pain in abdominal surgery in Spain. A multicentre drug utilization study. Br J Clin Pharmacol 1999;47(6):667-73.

[11] Rambod M, Sharif F, Pourali-Mohammadi N, et al. Evaluation of the effect of Benson's relaxation technique on pain and quality of life of haemodialysis patients: a randomized controlled trial. Int J Nurs Stud 2014;51(7):964-73.

[12] Rambod M, Pasyar N, Sharif F, et al. The effect of relaxation technique on physical activity of hemodialysis patients. Iran Journal of Nursing 2014;27(90):22-32.
[13] Ali A, Rosenberger L, Weiss TR, et al. Massage therapy and quality of life in osteoarthritis of the knee: a qualitative study. Pain Med 2017;18(6):1168-75.

[14] Black JM, Hawks JH. Medical-surgical nursing. Elsevier Saunders 2005.

[15] Rodgers A, Walker N, Schug S, et al. Reduction of postoperative mortality and morbidity with epidural or spinal anaesthesia: results from overview of randomised trials. BMJ 2000;321(7275):1493.

[16] Smith TL, Litvack JR, Hwang PH, et al. Determinants of outcomes of sinus surgery: a multi-institutional prospective cohort study. Otolaryngol Head Neck Surg 2010;142(1):55-63.

[17] Sunshine W, Field TM, Quintino O, et al. Fibromyalgia benefits from massage therapy and transcutaneous electrical stimulation. J Clin Rheumatol 1996;2(1):18-22.

[18] Attias S, Schiff E. P02. 38. Effectiveness of reflexology in improving perioperative patient centered outcomes: a comparative effectiveness study. BMC Complementary and Alternative Medicine 2012;12(S1):P94.

[19] Embong NH, Soh YC, Ming LC, et al. Revisiting reflexology: concept, evidence, current practice, and practitioner training. J Tradit Complement Med 2015;5(4):197-206.

[20] Sliz D, Smith A, Wiebking C, et al. Neural correlates of a single-session massage treatment. Brain Imaging Behav 2012;6(1):77-87.

[21] Valiani M, Shiran E, Kianpour M, et al. Reviewing the effect of reflexology on the pain and certain features and outcomes of the labor on the primiparous women. Iranian J Nurs Midwifery Res 2010;15(Suppl 1):302-10. 